\title{
Assessment of manual material handling in a tile and ceramic factory using the National Institute for Occupational Safety and Health equation in 2016
}

\author{
Nadri H, MSc ${ }^{1}$, Fasih Ramandi F, MSc ${ }^{2 *}$ \\ 1- MSc in Occupational Health Engineering, Dept. of Occupational Health, School of Public Health, Shahid Beheshti \\ University of Medical Sciences, Tehran, Iran. 2- MSc Student in Occupational Health Engineering, Dept of Occupational \\ Health, Student Research Committee, Shahid Beheshti University of Medical Sciences, Tehran, Iran.
}

Received: December 2016, Accepted: January 2017

Background: Manual handling, lifting, or carrying of material is responsible for non-fatal injuries among employees in industries. It is the second most prevalent reported risk factor in workplaces that can lead to potential manual handling accidents and longer-term musculoskeletal disorders (MSDs). The aim of this study was the evaluation of manual material handling using the American National Institute for Occupational Safety and Health (NIOSH) equation in a tile and ceramic factory in Tehran, Iran, in 2016.

Material and Methods: This cross-sectional study was carried out in a tile and ceramic factory in Tehran, Iran, in 2016. Three tile production lines (A, B, and C) were selected. On each line, cartons were lifted from a conveyor and placed onto a pallet. The task variable data were measured and recorded according to the NIOSH equation.

Results: According to the results, composite-lifting index (CLI) value in all three lines exceeded 3 (3.34, 4.53, and 5.99, respectively, for lines $\mathrm{C}$, B, and A). The values of frequency-independent recommended weight limit (FIRWL) and single-task recommended weight limit (STRWL) in all tasks were less than load weight. In addition, values of frequency-independent lifting index (FILI) and single-task lifting index (STLI) in all tasks exceeded 1.0.

Conclusions: The results show that CLI value for these jobs exceeded 3, which means that a significant level of physical stress is associated with these jobs for nearly all workers. Both strength and endurance are a problem for many workers. Therefore, the first priorities of job redesign should be the decreasing of the physical demands through modifying the job layout, and decreasing the physiological demands through reducing the frequency rate or duration of continuous lifting.

Keywords: NIOSH, Ceramic, Industry

\section{Introduction}

Musculoskeletal disorders (MSDs) are defined as disorders in muscles, tendons, tendon sheaths, peripheral nerves, joints, bones, ligaments, and blood vessels that are either the result of repetitive stress over time or an immediate or acute trauma (such as slipping and falling). The symptoms of this disorder include discomfort, pain, fatigue, swelling, stiffness, and tingling. It should be noted that these signs are not certain indication of MSDs, but are a sign of the underlying conditions of these disorders that manifest if these conditions are not corrected (1-4). According to annual statistics of the Health and Safety Executive of the United Kingdom, MSDs constitute three-quarters of the relevant diseases, which exclusively affect back and upper limbs (5) and are reported to be responsible for 9.5 million lost work days (an average of about 17 days per case) (6).

\footnotetext{
* Corresponding author: Fatemeh Fasih Ramandi, Dept of Occupational Health, Student Research Committee, Shahid Beheshti University of Medical Sciences, Tehran, Iran.

E-mail: f.fa30h@gmail.com
} 
According to various studies, MSDs, such as low back pain, are prevalent among individuals with jobs involving manual handling of loads and heavy physical workloads. Repeated manual handling of loads for a long period of time can lead to fatigue, pain, and damage, as inappropriate postures, repetitive movements, and heavy labor, such as carrying or lifting heavy loads, are risk factors for damage caused by manual handling of loads (7-13). In fact, almost one-third of all industrial jobs in the United States of America include at least one manual handling of loads activity (14). The most common activity of manual handling of loads at the workplace is lifting loads (15) and is considered as the most stressful activity of manual handling of loads (16). According to the statistics published by the UK Health and Safety Executive, manual handling of loads is the second most commonly reported risk factor in workplaces with this factor (5). Therefore, researchers haves always sought the cause and prevention of MSDs due to the risk factors, as a significant relationship has been reported between the prevalence of these disorders and increased risk of occupational accidents due to manual handling $(8-10,17)$.

The American National Institute for Occupational Safety and Health (NIOSH) introduced the handling load equation in 1991 to determine the recommended weight limits and procedures of determining weight limits, which include the physiological, biomechanics, physical-psychological, and epidemiologic aspects of manual load lifting. This equation was presented in 1994 by the NIOSH under the name of load lifting system with the aim of reducing the amount of damage and the adverse effects of load lifting (12). In this model, different variables are used, such as horizontal, and vertical distance, load handling, angle of trunk rotation, frequency, and coupling hands on load (handle). It is used to determine the recommended weight limit so that the majority of healthy workers can lift over a period of time (up to 8 hours) without adverse effects of load handling on the back (18).

This study aimed to determine the parameters of manual handling of loads (single-tasking and multitasking) according to the NIOSH equation, and compare them to the recommended amounts in a ceramic tile factory in Tehran, Iran. These parameters include the recommended weight limit (RWL), lifting index (LI), frequency-independent recommended weight limit (FIRWL), singletask recommended weight limit (STRWL), frequency-independent lifting index (FILI), single-task lifting index (STLI), and composite lifting index (CLI). The results can be used as a guide for ergonomic design.

\section{Materials and Methods}

This cross-sectional study was carried out in a ceramic tile factory in Tehran, Iran, in 2015. In this study, to evaluate the status of manual handling of loads, the NIOSH equation was used to determine the recommended weight limits in manual handling of loads in 3 production lines (Packaging unit). Data analysis was performed using the Microsoft Excel 2007 software.

Risk assessment of manual handling of loads: To evaluate the risk factors of load lifting activities, the revised NIOSH lifting equation (RNLE) was used. In the first step, in the packaging unit and workers' station, parameters such as weight of tile packages, horizontal location $(\mathrm{H})$, vertical location $(\mathrm{V})$, vertical travel distance (D), asymmetry angle (A), frequency rate (F), lifting duration, and coupling component $(\mathrm{C})$ were measured for all workers. In the second step, based on the results of the first step, horizontal multiplier (HM), vertical multiplier (VM), distance multiplier (DM), asymmetry multiplier (AM), coupling multiplier (CM), and load constant (LC) were calculated (Table 1).

Thus, FIRWL, STRWL, FILI, STLI, and CLI were calculated in each task of every job in all investigated production lines according to the proposed formulas (Table 1). It should be 
noted that in calculation of FILI and STLI of tasks, maximum and mean lifted weight must be used, respectively. In this study, FILI and
STLI were calculated in all tasks of three production lines using constant weight of handled tiles.

Table 1: The American National Institute for Occupational Safety and Health equation and calculation method

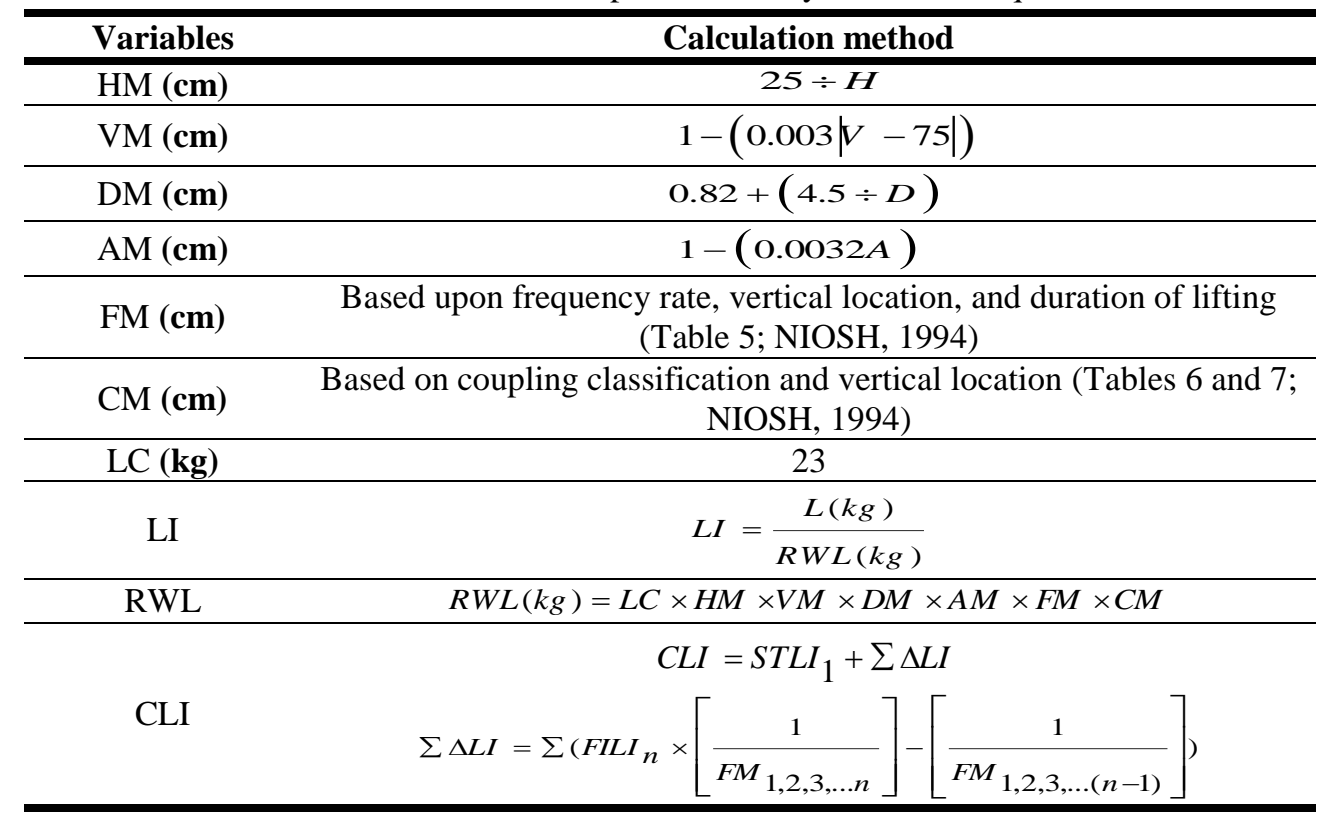

HM: Horizontal multiplier; VM: Vertical multiplier; DM: Distance multiplier; AM: Asymmetric multiplier; FM: Frequency multiplier; CM: Coupling multiplier; LC: Load constant; LI: Lifting index; RWL: Recommended weight limit CLI: Composite lifting index

Job description: Dimensions, weight of tile packages, pallet height, and conveyor height in the studied production lines are reported in table 2. In all three production lines, tile packages were placed on two floors on each pallet. Since these jobs include separate tasks and the task variables often change, multi-task lifting analysis procedure was used. Moreover, since all tasks required the controlling and repositioning of grip at the destination, analysis was performed at the origin and destination of lifting; in each production line, 2 tasks were analyzed on each floor. The workers could freely walk on the pallet to get close to it. Workers had a continuous working model ( 8 hours/day) with rest for lunch or possible production line halt.

\section{Results}

The results of all task multipliers of each production line are presented in table 3 , and the amounts of FIRWL, STRWL, FILI, and STLI for all tasks and CLI value for each job in the three production lines are given in table 4.

Table 2: Task variables

\begin{tabular}{ccccc}
\hline Line & $\begin{array}{c}\text { Tile package weight } \\
(\mathbf{k g})\end{array}$ & $\begin{array}{c}\text { Tile package dimension } \\
(\mathbf{c m})\end{array}$ & $\begin{array}{c}\text { Pallet height } \\
(\mathbf{c m})\end{array}$ & $\begin{array}{c}\text { Conveyor height } \\
(\mathbf{c m})\end{array}$ \\
\hline A & 22 & $60 \times 60$ & \multirow{2}{*}{10} & 70 \\
\hline B & 22 & $50 \times 50$ & & 95 \\
\cline { 1 - 2 } C & 14 & $40 \times 40$ & & 100 \\
\hline
\end{tabular}


Table 3: Computed Multiplier for Each Task

\begin{tabular}{|c|c|c|c|c|c|c|c|c|c|c|c|c|c|c|}
\hline \multirow[b]{2}{*}{ : } & \multirow[b]{2}{*}{$\begin{array}{l}\dot{z} \\
\frac{\pi}{2} \\
\frac{\pi}{\pi}\end{array}$} & \multirow[b]{2}{*}{ Object weight (kg) } & \multicolumn{2}{|c|}{ HM } & \multicolumn{2}{|c|}{ VM } & \multicolumn{2}{|c|}{ DM } & \multicolumn{2}{|c|}{$\mathbf{A M}$} & \multicolumn{2}{|c|}{ FM } & \multicolumn{2}{|c|}{$\mathbf{C M}$} \\
\hline & & & 范 & 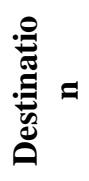 & 葛 & $=$ & 荡 & 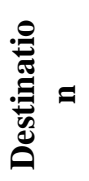 & 泀 & 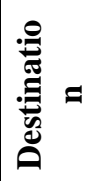 & 䔹 & 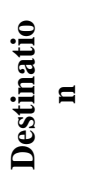 & 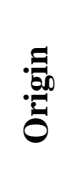 & 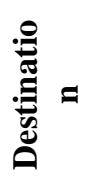 \\
\hline \multirow{2}{*}{$\mathbf{A}$} & 1 & \multirow{2}{*}{22} & 0.83 & 0.45 & 0.91 & 0.90 & 0.97 & 0.97 & 0.76 & \begin{tabular}{|l|}
0.90 \\
\end{tabular} & 0.68 & 0.68 & 1.00 & 1.00 \\
\hline & 2 & & 0.83 & 0.71 & 0.91 & 0.96 & 1.00 & 1.00 & 0.76 & \begin{tabular}{|l}
0.95 \\
\end{tabular} & 0.68 & 0.68 & 1.00 & 1.00 \\
\hline \multirow{2}{*}{ B } & 1 & \multirow{2}{*}{22} & 0.63 & 0.61 & 0.94 & 0.88 & 0.90 & 0.90 & 0.87 & 0.86 & 0.67 & 0.67 & 1.00 & 1.00 \\
\hline & 2 & & 0.63 & 0.61 & 0.94 & 0.97 & 1.00 & 1.00 & 0.87 & \begin{tabular}{|l|}
0.90 \\
\end{tabular} & 0.67 & 0.67 & 1.00 & 1.00 \\
\hline \multirow{2}{*}{ C } & 1 & \multirow[b]{2}{*}{14} & 0.66 & 0.60 & 0.93 & 0.87 & 0.88 & 0.88 & 0.90 & 0.81 & 0.67 & 0.67 & 1.00 & 1.00 \\
\hline & 2 & & 0.66 & 0.60 & 0.93 & 0.99 & 0.97 & 0.97 & 0.90 & \begin{tabular}{|l|l|}
0.84 \\
\end{tabular} & 0.67 & 0.67 & 1.00 & 1.00 \\
\hline
\end{tabular}

HM: Horizontal multiplier; VM: Vertical multiplier; DM: Distance multiplier; AM: Asymmetric multiplier; FM: Frequency multiplier; CM: Coupling multiplier

As shown in table 3, the lowest $\mathrm{HM}$ value (0.45) belonged to the destination of movement in task 1 in production line $\mathrm{A}$. The amount of VM was appropriate in all tasks.
FM had an approximately equal value in all three production lines. DM and CM values were appropriate and acceptable in all three lines.

Table 4: The frequency-independent recommended weight limit, single-task recommended weight limit, frequencyindependent lifting index, and single-task lifting index of each task and composite lifting index for each job

\begin{tabular}{|c|c|c|c|c|c|c|c|}
\hline Line & Task No. & & FIRWL & FILI & STRWL & STLI & CLI \\
\hline \multirow{4}{*}{$\mathbf{A}$} & \multirow{2}{*}{1} & Origin & 12.86 & 1.71 & 8.74 & 2.52 & \multirow{4}{*}{5.99} \\
\hline & & Destination & 8.20 & 2.68 & 5.58 & 3.94 & \\
\hline & \multirow{2}{*}{2} & Origin & 13.26 & 1.66 & 9.01 & 2.44 & \\
\hline & & Destination & 14.94 & 1.47 & 10.16 & 2.17 & \\
\hline \multirow{4}{*}{ B } & \multirow{2}{*}{1} & Origin & 10.55 & 2.09 & 7.07 & 3.11 & \multirow{4}{*}{4.53} \\
\hline & & Destination & 9.46 & 2.33 & 6.33 & 3.47 & \\
\hline & \multirow{2}{*}{2} & Origin & 11.78 & 1.87 & 7.89 & 2.79 & \\
\hline & & Destination & 12.30 & 1.79 & 8.24 & 2.67 & \\
\hline \multirow{4}{*}{$\mathbf{C}$} & \multirow{2}{*}{1} & Origin & 11.19 & 1.34 & 7.50 & 2.00 & \multirow{4}{*}{3.34} \\
\hline & & Destination & 8.46 & 1.77 & 5.67 & 2.65 & \\
\hline & \multirow{2}{*}{2} & Origin & 12.27 & 1.22 & 8.22 & 1.82 & \\
\hline & & Destination & 10.99 & 1.37 & 7.36 & 2.04 & \\
\hline
\end{tabular}

FIRWL: Frequency-independent recommended weight limit; FILI: Frequency-independent lifting index; STRWL: Singletask recommended weight limit; STIL: Single-task lifting index; CLI: Composite lifting index

As shown in table 4, CLI for lines A, B, and C was $5.99,4.53$, and 3.34 , respectively. FILI and STLI values exceeded 1 for all tasks in all three lines, as the range of changes were 1.222.68 , and 1.82-3.94, respectively. Furthermore, FIRWL and STRWL values of all tasks were less than the weight of tile packages; in production lines $\mathrm{A}$ and $\mathrm{B}$, with tile packages' weight of $22 \mathrm{~kg}$, task 1 in production line A had the lowest STRWL with $5.58 \mathrm{~kg}$. In addition, in production line $\mathrm{C}$, with tile packages' weight of $14 \mathrm{~kg}$, the lowest STRWL was observed in task 1 with $5.67 \mathrm{~kg}$.

\section{Discussion}

Occupational biomechanical stressors play an important role in the development of low back pain. The RNLE has been introduced as a useful tool for the estimation of exposure to biomechanical stressors to low back pain and LI is a scale of biomechanical stressors for low back pain caused by lifting and lowering of 
loads in sub-tasks and CLI is an estimate of the stressors associated with all tasks. In fact, LI and CLI showed a significant exposureresponse relationship for low back pain (1922). CLI for jobs (in the range of 3.34-5.99) in all three production lines showed that these jobs are physically stressful for all healthy workers. As CLI values in all three product lines exceeded 3 (high-risk), the load lifting was very stressful and there was an increased risk of occurrence of low back pain caused by lifting loads for nearly all of the work forces. Researchers have reported a significant relationship between the risk of occurrence or prevalence of LBP, and LI or CLI of greater than $1.0(20,23-25)$. In comparison with CLI values of less than 1.0, odds ratio of selfreported LBP has been reported as 5.1 to 6.5 for CLI > 2.0 (26). However, in our study, the CLI ranged from 3.34 to 5.99 and LI or STLI from 1.89 to 3.94 , which were in high risk areas.

Load handling NIOSH equation has been used in many studies to evaluate manual handling of loads, their results were consistent with that of our study, and the values obtained were higher than the recommended limit $(14,27$, 28). These studies used their results for redesigning workstations for manual handling of loads $(29,30)$.

FIRWL reflects the compressive force and muscle strength demands for one task repetition; in this study, the FIRWL value in all tasks in all three lines was less than tile packages' weight. In addition, the least amount of FIRWL $(8.20 \mathrm{~kg})$ was in task 1 of production line A. FILI, regardless of the task's repetition frequency, determines the maximum biomechanical load imposed on the body and ability to identify different tasks with biomechanical requirements. In this study, FILI of all tasks exceeded 1. Therefore, in load movement destination in all three production lines (except in task 2 of production line A and task 2 of production line B), FILI values exceeded the value at the origin of lifting, regardless of the frequency of load lifting. The results show that all tasks in all three product lines (especially in the movement destination task 1 in production line $\mathrm{A}$ and the origin and destination of task 1 in production line $B$ ) have high stress in terms of force. Based on the results, FIRWL and FILI values in all tasks require considerable strength, although lifting frequency has not been considered in the results. It is clear that force is a problem in all tasks, because FILI values exceeded 1 in all cases. Thus, the total physical requirement of these jobs is primarily due to excessive force requirement rather than lifting frequency rate. Assuming that only one task was in progress, STRWL for that task reflected the overall requirements of that task. However, the amount of STRWL is useful in determining the excessive physical stress of a separate task. In this study, STRWL in all tasks in all three production lines were less than the tile packages' weight, and the least amount of STRWL $(5.58 \mathrm{~kg})$ belonged to task 1 in production line A. STLI can represent metabolic needs distributed among all tasks more accurately and is used to identify tasks with excessive physical requirement (Leading to fatigue) and to prioritize tasks based on the amount of physical stress. In this study, STLI exceeded 1 in all tasks and exceeded FILI values. Moreover, STRWL and STLI values showed that all tasks will be stressful when separately performed. Nevertheless, these values disregarded the combined effects of all tasks. Hence, ergonomic interventions are essential to reduce the power requirements of tasks; the most important of these measures is reduction of weight of handled packages.

Based on the results presented in table 3, the multipliers with the lowest value impose the largest penalties. Since the amount of HM was less than 1 in all tasks, especially in the destination movement of task 1 in production line A (Table 3), it is essential to reduce the distance between the load and the worker with the aim of removing any horizontal barrier in destination and origin of load lifting. Therefore, if the horizontal distance at destination $(55 \mathrm{~cm})$ is decreased $20 \mathrm{~cm}, \mathrm{HM}$ value will increase to 0.71 . Furthermore, 
following the changes in amounts, FIRWL (12.89), FILI (1.71), STRWL (8.77), and STLI (2.51) improved for this task and CLI (4.55) improved for this job.

According to the production process, it is not possible to reduce tile packages' size; thus, it is better to increase pallet height. For example, if the vertical travel in movement destination $(35 \mathrm{~cm})$ of task 1 in production line $\mathrm{B}$ increases to $60 \mathrm{~cm}, \mathrm{VM}$ will increase to 0.96 . Following these changes, the values of FIRWL (10.26), FILI (2.14), STRWL (6.87), and STLI (3.20) for this task and CLI (4.26) for this job will improve.

\section{Conclusion}

In redesigning, in addition to the correction of multiplier, reducing duration (lifting frequency) and weight of packages should receive special attention. For example, in line A, considering all other factors constant, if the combined weight of tile packages $(22 \mathrm{~kg})$ is reduced to $16 \mathrm{~kg}$, rotational substitution of the job with a lighter job is implemented to reduce lifting time to 1 to 2 hours, recovery period is provided for workers, and the frequency of lifting load is reduced to $1 \mathrm{lift} / \mathrm{minute}$, the repetition factor will increase to 0.88 . As a result of this reform, CLI will be reduced $38.2 \%$, and reach 3.70. On the other hand, in production line $\mathrm{A}$, if we consider the tile packages' weight and lifting frequency constant and change all other factors, including $\mathrm{HM}, \mathrm{VM}, \mathrm{DM}, \mathrm{AM}$, and $\mathrm{CM}$, to their ideal values (one), CLI will be reduced $54.3 \%$, and reach 2.73 . Thus, the results of this study indicated considerable levels of physical stress related to these jobs. Furthermore, they showed that the status of load handling can be improved by combined engineering and managerial changes in work processes.

\section{Acknowledgment}

We are grateful to the managers of tile and ceramic industry for their valuable and technical suggestions on the preparation of this paper.
Conflict of interest: None declared

\section{References}

1. Tinubu BM, Mbada ChE, Oyeyemi AL, Fabunmi AA. Work-related musculoskeletal disorders among nurses in Ibadan, South-west Nigeria: a cross-sectional survey. BMC Musculoskelet Disord 2010; 11:12. doi:10.1186/1471-2474-11-12

2. Punnett L, Wegman DH. Work-related musculoskeletal disorders: the epidemiologic evidence and the debate. $\mathrm{J}$ Electromyogr kinesiol 2004; 14(1):13-23.

3. Anghel M, Argesanu V, Talpos-Niculescu C, Lungeanu D. Musculoskeletal disorders (MSDs)-consequences of prolonged static postures. Journal of Experimental Medical \& Surgical Research 2007; 16(4):167-72.

4. Hayes M, Cockrell D, Smith DR. A systematic review of musculoskeletal disorders among dental professionals. Int J Dent Hyg 2009; 7(3):159-65.

5. HSE. Annual Report for Great Britain. London, Britain; Health and Safety Executive, Health and Safety Statistics; 2013. Available from:

http://www.hse.gov.uk/statistics/overall/hssh13 14.pdf

6. HSE. Health and Safety Statistics: 2014/15 annual release. London, Britain; National Statistics, Health and Safety Executive. 2015 Oct. Available from:

https://www.gov.uk/government/statistics/healt h-and-safety-statistics-201415-annual-release

7. Marras W. Occupational low back disorder causation and control. Ergonomics 2000; 43(7):880-902.

8. Garg A, Kapellusch JM. The Cumulative Lifting Index (CULI) for the revised NIOSH lifting equation quantifying risk for workers with job rotation. Hum Factors 2016; 58(5):683-94.

9. Sarkar K, Dev S, Das T, Chakrabarty S, Gangopadhyay S. Examination of postures and frequency of musculoskeletal disorders among manual workers in Calcutta, India. Int J Occup Environ Health 2016; 22(2):151-8.

10. Battevi N, Pandolfi M, Cortinovis I. Variable lifting index for manual-lifting risk assessment: a preliminary validation study. Hum Factors 2016; 58(5):1-14.

11. Torres Y, Viña S. Evaluation and redesign of manual material handling in a vaccine 
production centre's warehouse. Work 2012; 41(Suppl 1):2487-91.

12. Waters TR, Putz-Anderson V, Garg A. Applications Manual for the Revised NIOSH Lifting Equation. Cincinnati (OH): U.S. Department of Health and Human Services Public Health Service, Centers for Disease Control and Prevention, National Institute for Occupational Safety and Health, Division of Biomedical and Behavioral Science; 1994 Jan. DHHS (NIOSH) Publication. Report No. 94110.

13. Habibi E, Kazemi M, Safari Sh, Hassanzadeh A. The relationship between lifting capasity with the NIOSH equation and the risk of Musculoskeletal Disorders with the RULA method in health service personal of Isfahan, Iran. Journal of Health System Research 2012; 8(1):131-7.

14. Chung MK, Kee D. Evaluation of lifting tasks frequently performed during fire brick manufacturing processes using NIOSH lifting equations. Int J Ind Ergon 2000; 25(4):423-33.

15. Lin CJ, Wang SJ, Chen HJ. A field evaluation method for assessing whole body biomechanical joint stress in manual lifting tasks. Ind Health 2006; 44(4):604-12.

16. Mital A, Ramakrishnan A. A comparison of literature-based design recommendations and experimental capability data for a complex manual materials handling activity. Int $\mathbf{J}$ Ind Ergon 1999; 24(1):73-80.

17. Marras WS, Karwowski W. Fundamentals and assessment tools for occupational ergonomics. $2^{\text {nd }}$ ed. Boca Raton, Florida, United States: CRC Press; 2006. P.918-48.

18. Russell SJ, Winnemuller L, Camp JE, Johnson PW. Comparing the results of five lifting analysis tools. Appl Ergon 2007; 38(1):91-7.

19. Garg A, Boda S, Hegmann KT, Moore JS, Kapellusch JM, Bhoyar P, et al. The NIOSH lifting equation and low-back pain, Part 1: Association with low-back pain in the backworks prospective cohort study. Hum Factors 2014; 56(1):6-28.

20. Waters TR, MacDonald LA, Hudock SD, Goddard DE. Provisional recommended weight limits for manual lifting during pregnancy. Hum Factors 2014; 56(1):203-14.

21. Garg A, Kapellusch JM, Hegmann KT, Moore JS, Boda S, Bhoyar P, et al. The NIOSH lifting equation and low-back pain, Part 2:
Association with seeking care in the backworks prospective cohort study. Hum Factors 2014; 56(1):44-57.

22. Kapellusch JM, Garg A, Boda S, Hegmann KT, Moore JS, Thiese MS, et al. Association between lifting and use of medication for low back pain: results from the backworks prospective cohort study. J Occup Environ Med 2014; 56(8):867-77

23. Boda S, Garg A, Campbell-Kyureghyan N. Can the revised NIOSH lifting equation predict low back pain incidence in a "90-day-painfree-cohort"? Proc Hum Fact Ergon Soc Annu Meet 2012; 56:1178-82. doi: 10.1177/1071181312561256

24. Waters TR, Lu ML, Piacitelli LA, Werren D, Deddens JA. Efficacy of the revised NIOSH lifting equation to predict low back pain due to manual lifting: expanded cross-sectional analysis. J Occup Environ Med 2011; 53(9):1061-7.

25. Marras WS, Fine LJ, Ferguson SA, Waters TR. The effectiveness of commonly used lifting assessment methods to identify industrial jobs associated with elevated risk of low-back disorders. Ergonomics 1999; 42(1):229-45.

26. $\mathrm{Lu} \mathrm{ML}$, Waters TR, Krieg E, Werren D. Efficacy of the revised NIOSH lifting equation to predict risk of lowback pain associated with manual lifting: A one-year prospective study. Hum Factors 2014; 56(1):73-85.

27. Varmazyar S, Sayrafi HS, Nikpay A. Assessing the recommended weight limit in manual carrying of loads in packaging lines of a factory in Qazvin. The Journal of Qazvin University of Medical Sciences 2011; 15(2):78-85.

28. Okimoto MLLR, Teixeira ER. Proposed procedures for measuring the lifting task variables required by the revised NIOSH lifting equation - a case study. Int J Ind Ergon 2009; 39(1):15-22.

29. Dormohammadi A, Amjad-Sardrudi H, Motamedzade M, Dormohammadi R, Musavi S. Ergonomics intervention in a tile industry: a case of manual material handling. Journal of Research Health Sciences 2012; 12(2):109-13.

30. Torres Y, Viña S. Evaluation and redesign of manual material handling in a vaccine production centre's warehouse. Work 2012; 41 (Suppl 1):2487-91. 